\title{
INTERNATIONAL ASSET ALLOCATION: A NEW PERSPECTIVE
}

by

\author{
Abraham LIOUI* \\ and \\ Patrice PONCET ${ }^{* *}$
}

First draft: December 13, 1999

This draft: October 15, 2000

\footnotetext{
${ }^{\circ}$ We thank Jérome Detemple, Bernard Dumas, Harald Hau and Roland Portait for useful remarks on a preliminary version.

* Bar-Ilan University

${ }^{* *}$ University of Paris-I Sorbonne and ESSEC

Corresponding author: Pr. Patrice Poncet, ESSEC, Département Finance, Avenue Bernard Hirsch, B.P. 105, 95021 Cergy-Pontoise Cedex, France. Tel: 33 (0) 1344330 26. Fax: 33 (0) 134433001. E-mail: Poncet@essec.fr
} 


\begin{abstract}
We consider an international economy where purchasing power parity (PPP) is violated and financial asset returns and exchange rates follow, in real terms, general diffusion processes driven by $\mathrm{K}$ state variables. A country-specific representative individual trades on available assets to maximize the expected utility of her final consumption. Her optimal strategy is shown to contain, in addition to the usual speculative component, only two hedging components, however large is $\mathrm{K}$. The first one is associated with domestic interest rate risk and the second one with the risk brought about by the co-movements of the interest rates and the market prices of risk. The implementation of the optimal strategy is thus much easier, as it involves estimating the characteristics of the yield curve and the market prices of risk only rather than those of numerous (a priori unknown) state variables. Thus, as to the necessity for rational investors to account for predictability in their optimal portfolio strategy, our results make it much easier than the traditional decomposition à la Merton. Since one hedging term depends on interest rate differentials across countries and encompasses hedging against PPP deviations, our decomposition turns to be also an elegant way to achieve optimal (indirect) currency risk hedging as opposed to usual ad hoc route to achieve such a hedging component followed by previous studies. Therefore, our decomposition gives new insights as to the pricing of foreign exchange risk at equilibrium.
\end{abstract}

JEL: G11, G13.

Keywords: International Portfolio Theory; Interest rate risk; Currency risk premium; Market price of risk; Asset return predictability. 


\section{Introduction}

This paper addresses the issue of optimal international portfolio allocation in a general multiperiod model where, in particular, exchange rate and interest rate risks are present. It posits an international economy where real exchange rates, real interest rates and real stock price changes follow general stochastic processes whose drifts and diffusion parameters are driven by an arbitrary number of state variables. Investors thus face a stochastic investment opportunity set ${ }^{1,2}$. A (reference country, or "domestic") representative investor trades on stocks, bonds and bills issued in various national economies in order to maximize the expected utility of his or her terminal wealth. The traditional solution to the problem is derived by using the stochastic dynamic programming technique pioneered in finance by Merton. The investor's optimal portfolio strategy is known to contain a speculative element and as many Merton-Breeden terms as there are state variables ${ }^{3}$. The latter are hedging devices against the unfavorable shifts in their investment opportunity set brought about by the state variables. However, while the speculative component is well identified and easy to interpret and work out, the implementation of the Merton-Breeden components is problematic as the investor must identify first all the relevant state variables and then estimate their distribution characteristics. Fama (1998) shows that, ignoring estimation problems, it is

\footnotetext{
${ }^{1}$ It is important to stress that early attempts, discussed in the remarkable and still very relevant survey by Adler and Dumas (1983), essentially focused on stocks. The analysis was conducted either in a discrete one-period mean-variance framework, which could not allow for stochastic interest rates, or in continuous time with constant interest rates and constant or deterministic drift and diffusion parameters for the stocks.

${ }^{2}$ Real exchange rates are assumed not to be equal to (the constant) one because of violations of Purchasing Power Parity (PPP). The latter may be due to differences in consumption tastes or to various imperfections related to sovereignty, such as taxes and border controls, that generate differences in the prices of the various goods to which investors have access. Consequently, expected real returns on two "equivalent" assets denominated in two different currencies will not be equal. Even a casual observation of real exchange rates demonstrates that they vary significantly over time and substantially differ in cross-sections.

${ }^{3}$ See Merton (1973) and Breeden (1979). When utility functions are logarithmic, however, all Merton-Breeden terms vanish, due to the myopia that then characterizes the investors' behavior.
} 
possible to find the set of state variables that are priced when the state variables are identified, but virtually impossible to do so when they are not, even though their number is known. This makes the implementation of the investor strategy difficult if not impossible.

Consequently, we follow a different route and use the martingale approach and the methodology developed by Cox and Huang $(1989,1991)$. The investor's optimal strategy is shown to be much simpler than in the traditional analysis. Indeed, it includes, in addition to the speculative component, two hedging elements only, however large is the postulated number of state variables. These two, novel, terms are akin to but different from the usual Merton-Breeden hedges. The first one is shown to be associated with domestic interest rate risk. The second one is associated with the risk brought about by the co-movements of the domestic interest rates and the international market prices of risk. Since this component depends on real interest rate differentials across countries and/or real exchange rate fluctuations, it encompasses hedging against violations of the Purchasing Power Parity (PPP). This new decomposition sheds a new light on the twin issues of the pricing of real exchange rate risk at equilibrium and the (partial) predictability of international asset returns.

In the absence of barriers to international investment and in the presence of exact PPP, the standard one-factor Asset Pricing Model is known to hold internationally. However, when PPP is violated, expected real returns differ and exchange risk is priced. Following Solnik (1974), Sercu (1980), and Stulz (1981), the international asset pricing model of Adler and Dumas (1983) exhibits, in addition to the risk premium associated with the market portfolio, risk premiums based upon the covariances of asset returns with exchange rates. The thus suggested direct inclusion of exchange risk(s) in a multi-factor pricing model is empirically examined by Jorion (1990, 1991), Bodnar and Gentry (1993), Cooper and Kaplanis (1994), Choi and Prasad (1995) and He and Ng (1998) among others. Dumas and Solnik (1995) use a conditional model that allows for time variation in the rewards for currency risk. Their results for the equities and currencies of the world's four largest stock markets support the existence of exchange risk premiums. Vassalou (2000) provides some tests of unconditional restrictions implied by this inclusion and finds support also for the pricing of foreign exchange risk in stock returns. De Santis and Gérard (1998) analyze the equity and Eurocurrency deposit markets of four major countries (Germany, Japan, the United Kingdom and the United States). A version of the international CAPM that includes both worldwide market risk and foreign exchange risk is strongly supported. With the exception of the U.S. stock market, the premium for currency risk often represents a significant fraction of the total premium. Not 
surprisingly, while for stocks the average premium for currency risk is a small fraction of the average total premium, most of the premium associated with Euro-deposits is compensation for currency risk exposure. Similarly, in their study of the Japanese stock market, Choi, Hiraki and Takezawa (1998) use a three-factor model and assume directly that one factor influencing the $\mathrm{j}^{\text {th }}$ asset nominal excess return is an exchange risk factor. The other factors are the market risk factor and an interest rate risk factor. In both papers, the components of the risk premiums are shown to vary significantly over time. Domowitz, Glen and Madhavan (1998), using an interesting methodology, find similarly in the Mexican government debt market that the currency (peso) risk premium is economically significant, time varying and persistent.

However, the models quoted above either are special cases with a constant investment opportunity set or use "ad hoc" state variables to exhibit foreign exchange risk pricing. For instance, Adler and Dumas (1983) substitute an indirect utility function that depends on both nominal consumption and a random price index (or inflation rate) for the direct utility function that depends on real consumption ${ }^{4}$. Inflation rates differing across economies, PPP is violated $^{5}$. Since these rates play the role of state variables, currency risk premiums are obtained. In our more general setting, we show that, in the investor's optimal strategy, currency risk is not hedged per se. Rather, it is indirectly hedged through the more general component that hedges against the random fluctuations of the market prices of risk for the various traded assets ${ }^{6}$. Consequently, currency risk will not be priced per se, but will be indirectly through the pricing of this more general risk. On the contrary, the first hedging component of the optimal strategy being a hedge against domestic interest rate risk, the latter risk will be priced in a direct manner. Thus, our findings provide theoretical support to empirical models such as the one postulated by Choi et al. (1998).

Our new decomposition also provides new insights regarding the issue of asset return predictability. While the question of why exactly returns are (partially) predictable is still

\footnotetext{
${ }^{4}$ Theirs thus is a special case with only one state variable (the domestic inflation rate) for the reference country investor.

${ }^{5}$ Therefore, in a way, their national representative investor does suffer from money illusion.

${ }^{6}$ This hedging component will degenerate into a pure currency risk hedging component if the drifts and/or volatilities of the real exchange rate dynamics are stochastic while all the other opportunity set parameters are deterministic.
} 
debated, modern asset pricing theories link this return predictability to hedging demands of investors. Different sensitivities of asset returns to the underlying state variables that generate time-varying market returns cause risk premiums on the assets to differ. Accordingly, the additional risk premiums that are attributable to currency risk hedging will contribute to this predictability ${ }^{7}$. More generally, mounting empirical evidence suggests that, in contrast with a long tradition of results, asset returns are (at least partially) predictable. Following the lead of De Bondt and Thaler (1985), Chen, Roll and Ross (1986) and Fama and French (1989), recent research ${ }^{8}$ has provided strong evidence that stock returns are partially persistent ${ }^{9}$. Similarly, evidence reported by Fama and Bliss (1986) and more recently by Cochrane (1999) suggests that the expectations hypothesis for bond returns seems to perform poorly, at least at short (one year) horizons. On the same grounds, the predictability of international equity returns has been empirically tested by Harvey (1991), Bekaert and Hodrick (1992), Ferson and Harvey (1993), Lamont (1998) and Fama and French (1998). Ignoring this predictability may lead to important welfare losses. For example, the empirical work of Glen and Jorion (1993) strongly suggests that international portfolios hedged against currency risks outperform (in a mean-variance sense) equivalent non-hedged ones, the measure of performance being the Sharpe ratio. Also, two studies by Solnik $(1993,1998)$ on international equity portfolios indicate that, if in the very long run hedging currency risk is unimportant, in the short or medium term, there is room for optimal, investor specific, currency risk hedging. More generally, Balduzzi and Lynch (1999) have recently shown that the (utility) costs of behaving myopically and ignoring predictability can be substantial. Finally, all the risk premiums have consistently been shown to vary over time and consequently the length of the investor's horizon is a crucial parameter, as argued by Barberis (2000). For instance, Brennan, Schwartz and Lagnado (1997) found that (longer horizon) portfolio strategies that take into account the predictability of asset returns significantly outperform (short horizon) portfolio strategies that ignore it.

\footnotetext{
${ }^{7}$ For example, Hodrick, $\mathrm{Ng}$ and Sengmueller (1999) find some recent evidence for the role of hedging demands in explaining the returns on the G7-country stock market indices.

${ }^{8}$ See Jegadeesh and Titman (1993), Flood, Hodrick and Kaplan (1994), Fama and French (1993, 1996) and Cochrane (1997), among others.

${ }^{9}$ This does not necessarily imply that mechanical trading rules will always, or even sometimes, beat the market since transaction and information costs must be taken into account in real life situations.
} 
Since ignoring the partial predictability of asset returns in designing portfolio strategies may lead to substantial losses, Fama's (1998) above-mentioned critique makes optimal investment decisions difficult. Our proposed decomposition eases substantially the implementation of the optimal strategy since it involves estimating the characteristics of the domestic yield curve and the international market prices of risk only, rather than those of numerous and a priori unknown state variables. In addition, the investor's time horizon is shown explicitly to play a crucial role in the optimal strategy design, in sharp contrast with the literature in continuous time in which only an instantaneous horizon comes into play. More precisely, we show that the maturity relevant for the two hedging terms coincides with the investor's horizon, and that there is no need to hedge against instantaneous fluctuations of the state variables.

The remainder of the paper is organized as follows. Section II presents the economic framework and details the main assumptions of the model. In Section III, we derive, discuss and interpret the optimal portfolio strategy of an investor whose utility function exhibits Constant Relative Risk Aversion (CRRA), contrasting the (non-myopic) isoelastic and the (myopic) logarithmic cases. Section IV examines the various implications of these results regarding the currency risk premium puzzle and the predictability of asset returns. Section V concludes and offers some suggestions for possible extensions.

\section{The economic framework}

The international financial market which investors have access to is frictionless and trading takes place continuously over the time interval $\left[0, \tau_{\mathrm{E}}\right]$, where $\tau_{\mathrm{E}}$ is the horizon of the international economy. There are $\mathrm{M}$ countries (economies) and $\mathrm{N}$ sources of risk across them. The latter are represented by $\mathrm{N}$ independent Brownian motions $\left\{\mathrm{Z}_{\mathrm{i}}(\mathrm{t}) ; \mathrm{t} \in\left[0, \tau_{\mathrm{E}}\right] ; \mathrm{i}=1, \ldots \mathrm{N}\right\}$ defined on a complete probability space $(\Omega, \mathrm{F}, \mathrm{P})$ where $\Omega$ is the state space, $F$ is the $\sigma$-field representing measurable events and $\mathrm{P}$ is the historical probability measure. All the processes defined below are diversely affected by these sources of risk and adapted to the augmented filtration generated by the $\mathrm{N}$ Brownian motions. This filtration is noted $\mathbf{F} \equiv\left\{\mathrm{F}_{\mathrm{t}}\right\}_{\mathrm{t} \in\left[0, \tau_{\mathrm{E}}\right]}$ and satisfies the usual conditions ${ }^{10}$. As often in the martingale approach to the yield curve, all the term structures are characterized by the dynamics of the relevant instantaneous forward

\footnotetext{
${ }^{10}$ The $\sigma$-field contains the events whose probability with respect to $\mathrm{P}$ is null. See for instance Karatzas and Shreve (1991).
} 
interest rates. Financial integration between the economies implies in particular that all the yield curves affect the risk and expected return on all available assets.

The following additional assumptions provide the necessary details.

Assumption set 1: Each country $\mathrm{j}(\mathrm{j}=1, \ldots, \mathrm{M})$ produces one consumption good from one technology. Therefore, without much loss of generality, only one stock (index) in each country is available for trade. In each economy, the numéraire is the consumption good so that every domestic variable is expressed in real terms from the domestic investor's viewpoint. The reference economy, $\mathrm{j}=1$, is the home country of our investor.

Assumption set 2: The drifts and diffusion parameters of all stochastic processes defined below depend on an unspecified number $\mathrm{K}$ of state variables $\mathrm{X}(\mathrm{t})$. The latter evolve through time according to the following stochastic differential equation (SDE):

$$
d X(t)=\delta(t, X(t)) d t+\psi(t, X(t)) d Z(t)
$$

where $\delta$ is a $(\mathrm{K} \times 1)$ vector and $\psi$ is a $(\mathrm{K} \times \mathrm{N})$ matrix. Note that some asset prices and/or interest rates defined below [in particular the spot interest rate prevailing in the reference country] may themselves belong to the set of the $\mathrm{K}$ state variables. For brevity, the dependence of a variable on $X(t)$ will be formally ignored, e.g. $f(t, \tau, X(t))=f(t, \tau)$, unless ambiguity arises.

Assumption set 3: In each country, the domestic, real, instantaneous forward rate solves the following SDE:

$$
\mathrm{df}_{\mathrm{j}}(\mathrm{t}, \mathrm{T})=\mu_{\mathrm{j}}(\mathrm{t}, \mathrm{T}, \mathrm{X}(\mathrm{t})) \mathrm{dt}+\sum_{\mathrm{i}=1}^{\mathrm{N}} \mathrm{v}_{\mathrm{ji}}(\mathrm{t}, \mathrm{T}, \mathrm{X}(\mathrm{t})) \mathrm{dZ} \mathrm{Z}_{\mathrm{i}}(\mathrm{t}) \quad \mathrm{j}=1, \ldots, \mathrm{M}
$$

where, for brevity, the drift and diffusion parameters will sometimes be noted $\mu_{\mathrm{j}}(\mathrm{t})$ and $v_{\mathrm{ji}}(\mathrm{t})$, respectively. We thus use a model for the yield curves à la Heath, Jarrow and Morton (1992), albeit a general version in which all drifts and diffusion parameters depend on the state variables, in the spirit of the recent paper by de Jong and Santa Clara (1999). This characterization is very general and, in particular, can be specialized to preclude forward rates to take on negative values. The drifts $\mu_{\mathrm{j}}(\mathrm{t})$ are assumed to satisfy the necessary 
conditions so that each equation (2) has a unique solution ${ }^{11,12}$. Also, it is readily seen that all the real yield curves are correlated, but that correlation is imperfect.

The real spot rate $r_{j}(t)$ is then such that $r_{j}(t)=f_{j}(t, t)$ and the locally riskless asset (money market account), starting at $\mathrm{B}_{\mathrm{j}}(0)=1$, is such that:

$$
B_{j}(t)=\exp \left\{\int_{0}^{t} r_{j}(s) d s\right\} \quad j=1, \ldots, M
$$

Consider now a default-free pure discount bond issued in country $\mathrm{j}$ and maturing at time $\tau_{\mathrm{j} \ell}<\tau_{\mathrm{E}}$. Its price at $\mathrm{t}<\tau_{\mathrm{j} \ell}$ is equal to:

$$
\mathrm{P}_{\mathrm{j} \ell}\left(\mathrm{t}, \tau_{\mathrm{j} \ell}\right)=\exp \left\{-\int_{\mathrm{t}}^{\tau_{\mathrm{j} \ell}} \mathrm{f}_{\mathrm{j}}(\mathrm{t}, \mathrm{T}) \mathrm{dT}\right\}
$$

and, applying Itô's lemma, the dynamics of its price is given by:

$$
\frac{\mathrm{dP}_{\mathrm{j} \ell}\left(\mathrm{t}, \tau_{\mathrm{j} \ell}\right)}{\mathrm{P}_{\mathrm{j} \ell}\left(\mathrm{t}, \tau_{\mathrm{j} \ell}\right)}=\left[\mathrm{b}_{\mathrm{j} \ell}\left(\mathrm{t}, \tau_{\mathrm{j} \ell}, \mathrm{X}(\mathrm{t})\right)+\mathrm{r}_{\mathrm{j}}(\mathrm{t}, \mathrm{X}(\mathrm{t}))\right] \mathrm{dt}+\sum_{\mathrm{i}=1}^{\mathrm{N}} \sigma_{\mathrm{P}_{\mathrm{j} i \mathrm{i}}}\left(\mathrm{t}, \tau_{\mathrm{j} \ell}, \mathrm{X}(\mathrm{t})\right) \mathrm{dZ} \mathrm{Z}_{\mathrm{i}}(\mathrm{t})
$$

where one need not specify the risk premium $b_{\mathrm{j} \ell}\left(\mathrm{t}, \tau_{\mathrm{j} \ell}, \mathrm{X}(\mathrm{t})\right)$ associated with the bond returns for the rest of the analysis, and the $\sigma_{\mathrm{P}_{\mathrm{j} \ell \mathrm{i}}}\left(\mathrm{t}, \tau_{\mathrm{j} \ell}\right)$, short notation for $\sigma_{\mathrm{P}_{\mathrm{j} \ell \mathrm{i}}}\left(\mathrm{t}, \tau_{\mathrm{j} \ell}, \mathrm{X}(\mathrm{t})\right)$, are functionally related to the $v_{\mathrm{ji}}(\mathrm{t})$ present in equation (2).

Finally, the real price of the stock (index) issued in economy $\mathrm{j}$ obeys the following SDE:

$$
\frac{d S_{j}(t)}{S_{j}(t)}=\mu_{S_{j}}(t, X(t)) d t+\sum_{i=1}^{N} \sigma_{S_{j i}}(t, X(t)) d Z_{i}(t) \quad j=1, \ldots, M
$$

These stocks do not pay dividends between 0 and $\tau_{\mathrm{E}}$.

Assumption 4: The real spot exchange rate $\mathrm{e}_{\mathrm{j}}(\mathrm{t})$ between the reference currency and country $\mathrm{j}$ currency $(\mathrm{j}=2, \ldots, \mathrm{M})$ evolves through time according to:

$$
\frac{d e_{j}(t)}{e_{j}(t)}=\mu_{e_{j}}(t, X(t)) d t+\sum_{i=1}^{N} \sigma_{e_{j i}}(t, X(t)) d Z_{i}(t) \quad j=2, \ldots, M
$$

\footnotetext{
${ }^{11}$ See conditions C.1 page 80 and C.2 page 81 of Heath et al. (1992).

${ }^{12}$ To avoid tedious repetitions, we mention this only once although it applies to all relevant stochastic differential equations.
} 
Note that this specification allows the exchange rate to be influenced by sources of risk that affect none of the yield curves, if one so desires. These sources of risk could summarize the various exogenous shocks affecting the real exchange rates such as real shocks brought about by interactions between the economies considered here and other countries. Obviously, if there were no deviations from PPP in this model, all drifts $\mu_{e_{j}}$ and diffusion parameters $\sigma_{\mathrm{e}_{\mathrm{ji}}}$ would be nil.

Now, adopting the reference country investor's viewpoint, all foreign asset prices must be converted using the real exchange rates $e_{j}(t)$. All converted prices will be distinguished by the symbol $^{\wedge}$. For instance, $\hat{\mathrm{P}}_{\mathrm{j} \ell}\left(\mathrm{t}, \tau_{\mathrm{j} \ell}\right)$ is the price of the maturity $\tau_{\mathrm{j} \ell}$ foreign discount bond issued in country $\mathrm{j}(\neq 1)$ expressed in units of the reference country good. Thus, $\hat{\mathrm{P}}_{\mathrm{j} \ell}\left(\mathrm{t}, \tau_{\mathrm{j} \ell}\right)=$ $\mathrm{P}_{\mathrm{j} \ell}\left(\mathrm{t}, \tau_{\mathrm{j} \ell}\right) \mathrm{e}_{\mathrm{j}}(\mathrm{t})$, and applying Itô's lemma yields:

$$
\frac{\mathrm{dP}_{\mathrm{j} \ell}\left(\mathrm{t}, \tau_{\mathrm{j} \ell}\right)}{\hat{\mathrm{P}}_{\mathrm{j} \ell}\left(\mathrm{t}, \tau_{\mathrm{j} \ell}\right)}=\hat{\mathrm{b}}_{\mathrm{j} \ell}\left(\mathrm{t}, \tau_{\mathrm{j} \ell}\right) \mathrm{dt}+\sum_{\mathrm{i}=1}^{\mathrm{N}} \hat{\sigma}_{\mathrm{P}_{\mathrm{j} i \mathrm{i}}}\left(\mathrm{t}, \tau_{\mathrm{j} \ell}\right) \mathrm{dZ} \mathrm{Z}_{\mathrm{i}}(\mathrm{t}) \quad \mathrm{j}=2, \ldots, \mathrm{M}
$$

where $\hat{b}_{j \ell}\left(t, \tau_{j \ell}\right) \equiv b_{j \ell}\left(t, \tau_{j \ell}, X(t)\right)+r_{j}(t)+\mu_{e_{j}}(t, X(t))+\sum_{i=1}^{N} \sigma_{P_{j} i}\left(t, \tau_{j \ell}, X(t)\right) \sigma_{e_{j i}}(t, X(t))$

and

$$
\hat{\sigma}_{P_{j} f i}\left(t, \tau_{j \ell}\right) \equiv \sigma_{P_{j i i}}\left(t, \tau_{j \ell}, X(t)\right)+\sigma_{e_{j i}}(t, X(t)) \quad i=1, \ldots, N
$$

Similarly, we obtain for the money market accounts $\hat{B}_{j}(t)=B_{j}(t) e_{j}(t)$ and the stocks $\hat{S}_{j}(t)=S_{j}(t) e_{j}(t)$, respectively:

$$
\frac{d \hat{B}_{j}(t)}{\hat{B}_{j}(t)}=\hat{r}_{j}(t) d t+\sum_{i=1}^{N} \sigma_{e_{j i}}(t) d Z_{i}(t) \quad j=2, \ldots, M
$$

where $\hat{r}_{j}(t) \equiv \mu_{e_{j}}(t)+r_{j}(t)$, and:

$$
\frac{\mathrm{d} \hat{S}_{\mathrm{j}}(\mathrm{t})}{\hat{S}_{\mathrm{j}}(\mathrm{t})}=\hat{\mu}_{\mathrm{S}_{\mathrm{j}}}(\mathrm{t}) \mathrm{dt}+\sum_{\mathrm{i}=1}^{\mathrm{N}} \hat{\sigma}_{\mathrm{S}_{\mathrm{ji}}}(\mathrm{t}) \mathrm{dZ} \mathrm{Z}_{\mathrm{i}}(\mathrm{t}) \quad \mathrm{j}=2, \ldots, \mathrm{M}
$$

where $\hat{\mu}_{S_{j}}(t) \equiv \mu_{S_{j}}(t, X(t))+\mu_{e_{j}}(t, X(t))+\sum_{i=1}^{N} \sigma_{S_{j i}}(t, X(t)) \sigma_{e_{j i}}(t, X(t))$

and $\hat{\sigma}_{S_{j i}}(t) \equiv \sigma_{S_{j i}}(t, X(t))+\sigma_{e_{j i}}(t, X(t)) \quad i=1, \ldots, N$. 
Assumption set 5: The international financial market is free of frictions and arbitrage opportunities. Financial assets investors have access to include, in each country, a riskless asset, a stock and bonds of various maturities such that the market is complete. We further assume, without loss of generality, that our reference country investor trade L bonds per country. Hence we in fact assume that the number of traded assets ( $\mathrm{M}$ stocks, $\mathrm{M} \times \mathrm{L}$ bonds, and $\mathrm{M}$ money market accounts) is such that $2 \mathrm{M}+\mathrm{M} \times \mathrm{L}=\mathrm{N}+1$.

This assumption implies, in particular, that each term structure is driven by an arbitrary number of factors.

Since there is no arbitrage opportunity in this complete market, there exists a probability measure equivalent to $\mathrm{P}$ with respect to a given numéraire such that the prices expressed in terms of this numéraire are martingales. When the numéraire is the riskless asset yielding $\mathrm{r}_{1}(\mathrm{t})$, the probability measure, denoted by $\mathrm{Q}$, is the so-called "risk-neutral" probability. $\mathrm{Q}$ is constructed such that:

$$
\left.\frac{\mathrm{dQ}}{\mathrm{dP}}\right|_{\mathrm{F}_{\mathrm{t}}} \equiv \eta(\mathrm{t})=\exp \left\{-\int_{0}^{\mathrm{t}} \phi(\mathrm{s})^{\prime} \mathrm{dZ}(\mathrm{s})-\frac{1}{2} \int_{0}^{\mathrm{t}} \phi(\mathrm{s})^{\prime} \phi(\mathrm{s}) \mathrm{ds}\right\}
$$

where the ' denotes a transpose,

$$
\phi(t) \equiv \Lambda(t)^{-1}\left[\begin{array}{c}
\hat{r}(t)-r_{1}(t) 1_{M-1} \\
\hat{b}(t)-r_{1}(t) 1_{M} \\
\hat{\mu}_{S}(t)-r_{1}(t) 1_{M}
\end{array}\right]
$$

is the $(\mathrm{N} \times 1)$ vector of the market prices of risks, with $\hat{r}(t)$ the $((M-1) \times 1)$ vector of $\hat{r}_{j}(t)$, $\hat{b}(t)$ the $((M \times L) \times 1)$ vector of $\hat{b}_{j \ell}\left(t, \tau_{j \ell}\right), \hat{\mu}_{S}(t)$ the $(M \times 1)$ vector of $\hat{\mu}_{S_{j}}(t)^{13}$, and

$$
\Lambda(\mathrm{t}) \equiv\left[\begin{array}{c}
\Lambda_{\mathrm{e}}(\mathrm{t}) \\
\Lambda_{\mathrm{P}}(\mathrm{t}) \\
\Lambda_{\mathrm{S}}(\mathrm{t})
\end{array}\right]
$$

is the $(\mathrm{N} \times \mathrm{N})$ matrix of volatilities, with $\Lambda_{\mathrm{e}}(\mathrm{t})$ the $((\mathrm{M}-1) \times \mathrm{N})$ matrix of $\sigma_{\mathrm{e}_{\mathrm{ji}}}(\mathrm{t}), \Lambda_{\mathrm{P}}(\mathrm{t})$ the $((\mathrm{M} \times \mathrm{L}) \times \mathrm{N})$ matrix of $\hat{\sigma}_{\mathrm{P}_{\mathrm{j} i \mathrm{i}}}\left(\mathrm{t}, \tau_{\mathrm{j} \ell}\right)$ and $\Lambda_{\mathrm{S}}(\mathrm{t})$ the $(\mathrm{M} \times \mathrm{N})$ matrix of $\hat{\sigma}_{\mathrm{S}_{\mathrm{ji}}}(\mathrm{t})^{14}$.

\footnotetext{
${ }^{13}$ To ease the notation, we have set $\hat{b}_{1 \ell}\left(\mathrm{t}, \tau_{1 \ell}\right) \equiv \mathrm{b}_{1 \ell}\left(\mathrm{t}, \tau_{1 \ell}\right)$ and $\hat{\mu}_{\mathrm{S}_{1}}(\mathrm{t}) \equiv \mu_{\mathrm{S}_{1}}(\mathrm{t})$.

${ }^{14}$ Similarly, we have defined $\hat{\sigma}_{\mathrm{P}_{\mathrm{li}}}\left(\mathrm{t}, \tau_{\mathrm{l} \ell}\right) \equiv \sigma_{\mathrm{P}_{\mathrm{li}}}\left(\mathrm{t}, \tau_{\mathrm{l} \ell}\right)$ and $\hat{\sigma}_{\mathrm{S}_{\mathrm{li}}}\left(\mathrm{t}, \tau_{1}\right) \equiv \sigma_{\mathrm{S}_{\mathrm{li}}}\left(\mathrm{t}, \tau_{1}\right)$.
} 
Note that (i) $\mathrm{Q}$ is unique and $\Lambda(\mathrm{t})$ full rank since the market is complete, and (ii) the market price of risk $\phi(t)$ is in general a stochastic vector process ${ }^{15}$.

Assumption 6: All the portfolio strategies followed by investors are admissible ${ }^{16}$, in particular self-financing. These strategies consist in determining at each instant $t$ the number of units of all available assets. Note that only the reference country money market account is a (locally) riskless asset from our reference investor's viewpoint.

\section{The Optimal Portfolio Strategy}

We analyze first the reference country investor's problem. We solve it when her utility function is isoelastic, and then when it is logarithmic. Lastly, we discuss and interpret the optimal solutions.

\section{The investor's program}

The investor's horizon is noted $\tau$, with $\tau<\min \left(\tau_{\mathrm{j} \ell}\right)_{\mathrm{j} \ell \in[1, \mathrm{M} \times \mathrm{L}]}$, which ensures that all bonds are long-lived assets from her viewpoint. Her problem is to choose an optimal (expected utility maximizing) portfolio strategy, i.e. the number of units of the available domestic and foreign assets. As the investment opportunity set fluctuates randomly due to the presence of state variables, her utility function is assumed to exhibit constant relative risk aversion (CRRA) to ensure explicit solutions. This assumption is standard in the literature relative to the optimal asset allocation issue ${ }^{17}$. Since the instantaneous forward rates are Markovian, the thrust of our results would nevertheless be preserved under a more general HARA utility function. In this framework, however, no intuition is lost because of the CRRA assumption. Also, under the complete market assumption, taking intermediate consumption into explicit account would be easy but would not add anything to this intuition. In order for the elegant method pioneered

\footnotetext{
${ }^{15}$ The strong assumption according to which the market price of risk is deterministic is frequently encountered in the literature when explicit solutions are sought for. We will not need it.

${ }^{16}$ To save space, we do not specify the (well known) properties of admissible strategies. See Harrison and Kreps (1979), Harrison and Pliska (1981), Cox and Huang (1989) and Heath et al. (1992).

${ }^{17}$ See for instance the recent papers by Barberis (2000) or Balduzzi and Lynch (1999, 2000).
} 
by Pliska (1986) and Cox and Huang (1989) to be applicable, we further assume that all parameters in the model satisfy the necessary conditions for an optimal solution to exist.

The first CRRA utility function is the isoelastic utility such that:

$$
\mathrm{u}(\mathrm{V}(\tau, \omega))=\frac{1}{\alpha} \mathrm{V}(\tau, \omega)^{\alpha}, \quad \omega \in \Omega, \quad 0<\alpha<1
$$

where $(1-\alpha)$ is the (positive, smaller than one) constant of relative risk aversion.

The second CRRA function is the logarithmic utility that characterizes a Bernoulli investor and uniquely possesses the myopic property:

$$
\mathrm{u}(\mathrm{V}(\tau, \omega))=\operatorname{Ln}(\mathrm{cV}(\tau, \omega)), \quad \omega \in \Omega
$$

where $\mathrm{c}$ is a mere scale parameter. This case corresponds to the limit of the isoelastic utility function for $\alpha=0$. The relative risk aversion coefficient thus is equal to 1 .

The investor's problem is to choose the number of units of the locally riskless asset $\Gamma_{\mathrm{B}_{1}}(\mathrm{t})$, the numbers of units of the foreign (risky) money market accounts $\Gamma_{B_{j}}(t)$, for $j=2, \ldots, M$, and the numbers of risky bonds $\Gamma_{\mathrm{P}_{\mathrm{j} \ell}}(\mathrm{t})$ and of risky stocks $\Gamma_{\mathrm{S}_{\mathrm{j} \ell}}(\mathrm{t})$, for $\mathrm{j}=1, \ldots, \mathrm{M}$.

Her wealth $\mathrm{V}(\mathrm{t})$ at each time $\mathrm{t}$ thus is:

$$
V(t)=\sum_{j=1}^{M}\left[\Gamma_{B_{j}}(t) \hat{B}_{j}(t)+\sum_{\ell=1}^{L} \Gamma_{P_{j \ell}}(t) \hat{P}_{j \ell}\left(t, \tau_{j \ell}\right)+\Gamma_{S_{j}}(t) \hat{S}_{j}(t)\right]
$$

where here, by convention, $\hat{\mathrm{B}}_{1}(\mathrm{t}) \equiv \mathrm{B}_{1}(\mathrm{t}), \hat{\mathrm{S}}_{1}(\mathrm{t}) \equiv \mathrm{S}_{1}(\mathrm{t})$ and $\hat{\mathrm{P}}_{1 \ell}\left(\mathrm{t}, \tau_{1 \ell}\right) \equiv \mathrm{P}_{1 \ell}\left(\mathrm{t}, \tau_{1 \ell}\right)$ to ease the notation.

Using Itô's lemma, the wealth dynamics writes:

$$
d V(t)=(.) d t+\left[\Gamma_{B}(t)^{\prime} \hat{I}_{B}(t) \Lambda_{e}(t)+\Gamma_{P}(t)^{\prime} \hat{I}_{P}(t) \Lambda_{P}(t)+\Gamma_{S}(t)^{\prime} \hat{I}_{S}(t) \Lambda_{S}(t)\right] d Z(t)
$$

where $\Gamma_{B}(t)$ is the $((M-1) \times 1)$ vector of $\Gamma_{B_{j}}(t), \Gamma_{P}(t)$ is the $((M \times L) \times 1)$ vector of $\Gamma_{P_{j \ell}}(t)$, $\Gamma_{S}(t)$ is the $(M \times 1)$ vector of $\Gamma_{S_{j}}(t), \hat{I}_{B}(t)$ denotes the $((M-1) \times(M-1))$ diagonal matrix with elements $\hat{B}_{j}(t),(j=2, \ldots M), \hat{I}_{P}(t)$ is the $((M \times L) \times(M \times L))$ diagonal matrix with elements $\hat{\mathrm{P}}_{\mathrm{j} \ell}\left(\mathrm{t}, \tau_{\mathrm{j} \ell}\right), \hat{\mathrm{I}}_{\mathrm{S}}(\mathrm{t})$ is the $(\mathrm{M} \times \mathrm{M})$ diagonal matrix with elements $\hat{\mathrm{S}}_{\mathrm{j}}(\mathrm{t})$ respectively. 
Equivalently, (14) rewrites:

$$
\frac{d V(t)}{V(t)}=(.) d t+\left[\gamma_{B}(t)^{\prime} \Lambda_{e}(t)+\gamma_{P}(t)^{\prime} \Lambda_{P}(t)+\gamma_{S}(t)^{\prime} \Lambda_{S}(t)\right] d Z(t)
$$

where $\gamma_{\mathrm{y}}(\mathrm{t})^{\prime} \equiv \Gamma_{\mathrm{y}}(\mathrm{t})^{\prime} \hat{\mathrm{I}}_{\mathrm{y}}(\mathrm{t}) / \mathrm{V}(\mathrm{t})$, for $\mathrm{y}=\mathrm{B}, \mathrm{P}$ and $\mathrm{S}$, are expressed as proportions of total wealth. Our results thus are couched in terms of portfolio weights, as is usual in the literature.

We use the martingale approach to solve this problem. As log utility is a special case of isoelastic utility, one need not derive it explicitly. It will suffice to set $\alpha$ equal to zero in the optimal solution to the isoelastic case.

The investor's international portfolio problem then writes:

$$
\begin{aligned}
& \operatorname{Max} \quad \mathrm{E}^{\mathrm{P}}\left[\frac{\mathrm{V}(\tau)^{\alpha}}{\alpha}\right] \\
& \text { s.t. } \mathrm{E}^{\mathrm{P}}\left[\frac{\mathrm{V}(\tau)}{\mathrm{h}(\tau)}\right]=\mathrm{V}(0)
\end{aligned}
$$

where $0<\alpha<1[\alpha=0$ for $\log$ utility] and $h(\tau)$ is the value at date $t$ of the optimal growth portfolio.

Indeed, to simplify the computation of the investor's optimal strategy, we make use of $h(t)$, the numeraire, or optimal growth, portfolio, which makes the h-denominated value process of any admissible portfolio a martingale under the historical probability measure $\mathrm{P}^{18}$. Formally, $h(t)$ is defined as:

$$
\mathrm{h}(\mathrm{t}) \equiv \mathrm{B}_{1}(\mathrm{t}) \frac{\mathrm{dP}}{\mathrm{dQ}} \mid F_{\mathrm{t}}=\exp \left\{\int_{0}^{\mathrm{t}} \phi(\mathrm{s})^{\prime} \mathrm{dZ}(\mathrm{s})+\int_{0}^{\mathrm{t}}\left(\mathrm{r}_{1}(\mathrm{~s})+\frac{1}{2} \phi(\mathrm{s})^{\prime} \phi(\mathrm{s}) \mathrm{ds}\right)\right\}
$$

This well known numéraire portfolio is the Bernoulli investor's optimal portfolio.

\footnotetext{
${ }^{18}$ Long (1990).
} 


\section{Solutions}

Using Cox and Huang (1991) one can easily verify that program (16) has a unique solution. The first-order condition for an optimum writes:

$$
\mathrm{V}(\tau)=\lambda^{\frac{1}{\alpha-1}} \mathrm{~h}(\tau)^{\frac{1}{1-\alpha}}
$$

where the Lagrange multiplier $\lambda$ is characterized by:

$$
\mathrm{V}(0)=\lambda^{\frac{1}{\alpha-1}} \mathrm{E}^{\mathrm{P}}\left[\mathrm{h}(\tau)^{\frac{\alpha}{1-\alpha}}\right]
$$

In the $\log$ utility case $(\alpha=0), \mathrm{V}(0)=\lambda^{-1}$ and $\mathrm{V}(\tau)=\mathrm{h}(\tau) \mathrm{V}(0)$, which justifies the interpretation of $h(t)$ as the optimal growth portfolio.

It follows that:

$$
\frac{\mathrm{V}(\mathrm{t})}{\mathrm{h}(\mathrm{t})}=\mathrm{E}^{\mathrm{P}}\left[\frac{\mathrm{V}(\tau)}{\mathrm{h}(\tau)} \mid F_{\mathrm{t}}\right]=\lambda^{\frac{1}{\alpha-1}} \mathrm{E}_{\mathrm{t}}^{\mathrm{P}}\left[\mathrm{h}(\tau)^{\frac{\alpha}{1-\alpha}}\right]
$$

where $\mathrm{E}_{\mathrm{t}}[$.$] denotes the expectation conditional on the information F_{\mathrm{t}}$ available at date $\mathrm{t}$.

Thus optimal wealth at $\mathrm{t}$ is equal to:

$$
\mathrm{V}(\mathrm{t})=\lambda^{\frac{1}{\alpha-1}} \mathrm{~h}(\mathrm{t}) \mathrm{E}_{\mathrm{t}}^{\mathrm{P}}\left[\mathrm{h}(\tau)^{\frac{\alpha}{1-\alpha}}\right]=\left\{\lambda^{\frac{1}{\alpha-1}} \mathrm{~h}(\mathrm{t})^{\frac{1}{1-\alpha}}\right\} \mathrm{E}_{\mathrm{t}}^{\mathrm{P}}\left[\left(\frac{\mathrm{h}(\tau))^{\frac{\alpha}{1-\alpha}}}{\mathrm{h}(\mathrm{t})}\right)^{1}\right]
$$

Expression (18) calls for the following important remarks. First notice that, when utility is logarithmic $(\alpha=0)$, only the first term in brackets $\left\{\lambda^{-1} h(t)\right\}$ remains. For this reason, only a speculative term will appear in the investor's optimal strategy. In the isoelastic case, however, there exists a second term $\mathrm{E}_{\mathrm{t}}^{\mathrm{P}}[$.] that will generate dynamic hedging components in the strategy. To see this, rewrite equation (18) as:

$$
\mathrm{V}(\mathrm{t})=\left\{\lambda^{\frac{1}{\alpha-1}} \mathrm{~h}(\mathrm{t})^{\frac{1}{1-\alpha}}\right\} \mathrm{E}_{\mathrm{t}}^{\mathrm{P}}\left[\left(\frac{\mathrm{h}(\mathrm{t})}{\mathrm{h}(\tau)}\right)^{\frac{\alpha}{\alpha-1}}\right]
$$


This term turns out to be closely related to the pricing kernel under the historical probability P. Indeed, this pricing kernel is such that any future random cash-flow $\mathrm{y}(\mathrm{T})$ has an arbitragefree price at current date $t$ equal to : $y(t)=h(t) E_{t}^{P}\left[y(T) h(T)^{-1}\right]=E_{t}^{P}[y(T)(h(t) / h(T))]$.

If the investor has logarithmic utility $(\alpha=0)$, he will hold exactly the optimum growth portfolio (pricing kernel), such that he will not have to hedge against its random fluctuations. Otherwise $(\alpha \neq 0)$, he will find it optimal to hedge against random shifts of the drift and diffusion parameter of the pricing kernel. Hence, unless the latter are deterministic functions, there will be additional terms à la Merton-Breeden in the optimal strategy to hedge against unfavorable shifts in the investment opportunity set.

Now the term $\mathrm{E}_{\mathrm{t}}^{\mathrm{P}}[$.$] of equation (18) can be made explicit as follows:$

$$
\mathrm{E}_{\mathrm{t}}^{\mathrm{P}}\left[\left(\frac{\mathrm{h}(\tau)}{\mathrm{h}(\mathrm{t})}\right)^{\frac{\alpha}{1-\alpha}}\right]=\mathrm{E}_{\mathrm{t}}^{\mathrm{P}}\left[\left(\frac{\mathrm{B}_{1}(\tau) \eta(\tau)^{-1}}{\mathrm{~B}_{1}(\mathrm{t}) \eta(\mathrm{t})^{-1}}\right)^{\frac{\alpha}{1-\alpha}}\right]
$$

since, from the definition of $h(t)$ and the definition $(11), h(t)=B_{1}(t) \eta(t)^{-1}$. Then $V(t)$ writes:

$$
\mathrm{V}(\mathrm{t})=\left\{\lambda^{\frac{1}{\alpha-1}} \mathrm{~h}(\mathrm{t})^{\frac{1}{1-\alpha}}\right\}\left[\mathrm{E}_{\mathrm{t}}^{\mathrm{P}}\left[\left(\frac{\mathrm{B}_{1}(\tau)}{\mathrm{B}_{1}(\mathrm{t})}\right)^{\frac{\alpha}{1-\alpha}}\right] \cdot \mathrm{E}_{\mathrm{t}}^{\mathrm{P}}\left[\left(\frac{\eta(\tau)^{-1}}{\eta(\mathrm{t})^{-1}}\right)^{\frac{\alpha}{1-\alpha}}\right]+\operatorname{Cov}_{\mathrm{t}}\left[\left(\frac{\mathrm{B}_{1}(\tau)}{\mathrm{B}_{1}(\mathrm{t})}\right)^{\frac{\alpha}{1-\alpha}} ;\left(\frac{\eta(\tau)^{-1}}{\eta(\mathrm{t})^{-1}}\right)^{\frac{\alpha}{1-\alpha}}\right]\right]
$$

Thus the hedging component in big brackets stems from the existence of two particular sources of risk (plus the risk due to the generally non-zero correlation between the two): the interest rate risk related to the random evolution of the money market account value $B_{1}(t)$ accruing at the stochastic rate $r_{1}(t)$, and the risk associated with the random fluctuations of the market prices of risk (hereafter MPR) $\phi(t)$ that are embedded in the Radon-Nicodym derivative $\eta(\mathrm{t})$.

To put equation (19) in perspective, it is worth noting that: (i) even if the drifts and diffusion parameters relative to stocks and the risk premium and diffusion parameters relative to bonds were deterministic, the three types of risk would remain since the MPR $\phi(t)$ includes terms directly related to (stochastic) interest rates; (ii) even if one makes the frequently used but strong assumption that the MPR follows a deterministic process, the first source of risk is still 
present; (iii) if, on the other hand, one assumes deterministic interest rates, the second source of risk (MPR) remains, provided the drifts or volatilities relative to stocks and/or exchange rates are stochastic.

Equation (18) for wealth at time $\mathrm{t}$ can be written in a way that will shed light on the economic interpretation of the investor's optimal strategy:

$$
\begin{aligned}
\mathrm{V}(\mathrm{t}) & =\lambda^{\frac{1}{\alpha-1}} \mathrm{~h}(\mathrm{t}) \mathrm{E}_{\mathrm{t}}^{\mathrm{P}}\left[\mathrm{h}(\tau)^{\frac{\alpha}{1-\alpha}}\right]=\lambda^{\frac{1}{\alpha-1}} \mathrm{~h}(\mathrm{t})^{\frac{1}{1-\alpha}} \mathrm{P}_{1}(\mathrm{t}, \tau)^{\frac{\alpha}{\alpha-1}} \mathrm{E}_{\mathrm{t}}^{\mathrm{P}}\left[\left(\frac{\left.\left.\mathrm{P}_{1}(\mathrm{t}, \tau) \mathrm{h}(\tau) \mathrm{P}_{1}(\tau, \tau) \mathrm{h}(\mathrm{t})\right)^{\frac{\alpha}{1-\alpha}}\right]}{}\right]\right. \\
& =\lambda^{\frac{1}{\alpha-1}} \mathrm{~h}(\mathrm{t})^{\frac{1}{1-\alpha}} \mathrm{P}_{1}(\mathrm{t}, \tau)^{\frac{\alpha}{\alpha-1}} \mathrm{E}_{\mathrm{t}}^{\mathrm{P}}\left[\hat{\theta}(\mathrm{t}, \tau)^{\frac{\alpha}{\alpha-1}}\right]
\end{aligned}
$$

where we have introduced the price $\mathrm{P}_{1}(\mathrm{t}, \tau)$ of the (redundant, hence replicable) discount bond that is issued in the reference country and the maturity of which coincides with the investor's horizon.

This choice is not arbitrary since this bond is the only one for which $\mathrm{P}_{1}(\tau, \tau)=1$ (unit of the reference country currency). Now $\hat{\theta}(\mathrm{t}, \tau) \equiv \frac{\mathrm{P}_{1}(\tau, \tau) \mathrm{h}(\mathrm{t})}{\mathrm{P}_{1}(\mathrm{t}, \tau) \mathrm{h}(\tau)}$ is the Radon-Nicodym derivative associated with the change of numéraire from the growth optimum portfolio $h(t)$ to the discount bond price $\mathrm{P}_{1}(\mathrm{t}, \tau)$. In other words, $\hat{\theta}(\mathrm{t}, \tau)$ is the density that allows the prices of all risky assets using the bond price as numéraire to become martingales under this new probability measure. It is also the Arrow-Debreu price for one unit of the discount bond in every possible state of the world.

According to equation (20), part of the isoelastic investor's strategy will conveniently be analyzed as "including" the discount bond $\mathrm{P}_{1}(\mathrm{t}, \tau)$ as a hedging device against interest rate risk. Thus, the role of the investor's horizon will emerge in a natural and elegant way in the optimal portfolio strategy. Further discussion of the implications of this result will be provided in paragraph 3 below and in section IV.

Defining $\mathrm{E}_{\mathrm{t}}^{\mathrm{P}}\left[\hat{\theta}(\mathrm{t}, \tau)^{\frac{\alpha}{\alpha-1}}\right] \equiv \hat{\mathrm{J}}(\alpha ; \mathrm{t}, \tau)$ and applying Itô's lemma to $\hat{\mathrm{J}}($.$) yields:$ 


$$
\frac{\mathrm{d} \hat{\mathbf{J}}(.)}{\hat{\mathrm{J}}(.)}=(.) \mathrm{dt}+\sum_{\mathrm{i}=1}^{\mathrm{N}} \hat{\sigma}_{\mathrm{Ji}}(\alpha ; \mathrm{t}, \tau) \mathrm{dZ} Z_{\mathrm{i}}(\mathrm{t})
$$

where $\hat{\sigma}_{J}(\alpha ; t, \tau)^{\prime}$ is the $(1 \mathrm{x} \mathrm{N})$ diffusion vector of the process $d \hat{J}(.) / \hat{J}($.$) , and \hat{J}($.$) is the$ instantaneous conditional $(\alpha /(\alpha-1))$ "moment" of the Arrow-Debreu prices of the reference country bond of maturity $\tau$.

Applying Itô's lemma to equation (20) in turn yields:

$$
\frac{\mathrm{dV}(\mathrm{t})}{\mathrm{V}(\mathrm{t})}=(.) \mathrm{dt}+\left[\frac{1}{1-\alpha} \phi(\mathrm{t})^{\prime}-\frac{\alpha}{1-\alpha} \sigma_{\mathrm{P}_{1}}(\mathrm{t}, \tau)^{\prime}+\hat{\sigma}_{\mathrm{J}}(\alpha ; \mathrm{t}, \tau)^{\prime}\right] \mathrm{dZ}(\mathrm{t})
$$

where $\sigma_{\mathrm{P}_{1}}(\mathrm{t}, \tau)$ is defined in the same way as $\sigma_{\mathrm{P}_{\mathrm{j} \ell}}\left(\mathrm{t}, \tau_{\mathrm{j} \ell}\right)$.

Now, identifying the diffusion terms of admissible wealth (15) and optimal wealth (21) leads to the following proposition:

\section{Proposition:}

Given the assumptions of the model, the optimal strategy the isoelastic investor of the reference country follows is given by:

$$
\left[\begin{array}{l}
\gamma_{B}(t) \\
\gamma_{P}(t) \\
\gamma_{S}(t)
\end{array}\right]=\frac{1}{1-\alpha} \Lambda(t)^{-1} \phi(t)-\frac{\alpha}{1-\alpha} \Lambda(t)^{-1} \sigma_{P_{1}}(t, \tau)+\Lambda(t)^{-1} \hat{\sigma}_{J}(\alpha ; t, \tau)
$$

and the optimal strategy the logarithmic investor follows is given by:

$$
\left[\begin{array}{l}
\gamma_{B}(t) \\
\gamma_{P}(t) \\
\gamma_{S}(t)
\end{array}\right]=\Lambda(t)^{-1} \phi(t)
$$

\section{Discussion}

We comment first the more general, isoelastic, case. Note that all three components of the strategy (22) depend on the preference-dependent parameter $\alpha$, which is investor specific. Also note that the last two terms equally depend on the investor's horizon $\tau$.

The first component of the investor's strategy is the speculative element. Recalling from (11) the definition of the MPR $\phi(t)$ associated with the risky assets, this speculative part is a usual mean-variance type term. It is of course a decreasing function of the investor's risk aversion 
$(1-\alpha)$. Also, since the investor has access to the locally riskfree asset yielding $r_{1}(t)$, it is the risk premiums present in the definition of the MPR vector $\phi(t)$ that show up in the numerator instead of the drifts of the price processes.

Note at this point that there is no difference of nature between investing in domestic risky assets and investing in foreign ones. Both are required to span the sources of uncertainty present in the international economy and to allow for a first best optimum, and both are priced such that the trade-off between expected return and risk is compatible with equilibrium. Therefore, the usual interpretation according to which the position in foreign bonds is tantamount to plain currency risk hedging ${ }^{19}$ is at best misleading: if the investor wants to hedge, why would he invest in foreign assets in the first place?

The second and third terms of equation (22) differ markedly from what is offered in the (abundant) literature on inter-temporal portfolio choices. For instance, Merton $(1969,1971)$ or Adler and Dumas (1983), following the traditional route of stochastic dynamic programming leading to the Hamilton-Jacobi-Bellman equation, write the investor's value function as a function of the state variables and derive the optimal demands. In our setting, this would have produced $K$ hedges against the instantaneous risks associated with the $\mathrm{K}$ state variables. In contrast, our investor's strategy exhibits two hedging terms against what will be interpreted below as (i) the interest rate risk measured up to the investment horizon and (ii) a mixture of the (maturity $\tau$ ) bond price volatility and of the MPR volatility.

Indeed, the second ingredient in (22) is an informationally based component that hedges against unfavorable shifts in the investment opportunity set that are due to interest rate risk. Therefore, the rational investor wants to protect herself against situations in which her wealth is smaller because of such shocks. It is akin to (but different from) a standard MertonBreeden hedge component since the latter hedges against the random fluctuations of a particular state variable. In addition, our second component has here a distinctive feature: the asset that the investor implicitly uses is not the money market account which is common to all investors, but the discount bond whose maturity date coincides with her own investment horizon, $\mathrm{P}_{1}(\mathrm{t}, \tau)$. This result is intuitive in so far as she wishes to hedge against changes in her opportunity set for a time period that is not infinitesimal but extends up to her horizon, but

\footnotetext{
${ }^{19}$ See for instance Solnik (1974). This is not to say, as will be seen below, that currency-related hedging in the Merton-Breeden sense is absent from the strategy.
} 
not beyond ${ }^{20}$. Consequently, this hedging term tends to zero as the investor's horizon shrinks. It is important to notice (i) that this bond $\mathrm{P}_{1}(\mathrm{t}, \tau)$ is a synthetic asset which the investor could easily manufacture since the market is complete, and (ii) that this implicit synthetic asset is found endogenously as part of the solution to the investor's problem, as opposed to being included on a priori grounds in the investor's portfolio.

The last term in equation (22), although couched in rather abstract terms, also lends itself to various economic interpretations. As shown above, $\hat{\mathrm{J}}(\alpha ; \mathrm{t}, \tau)$ is related to the contingent Arrow-Debreu prices $\hat{\theta}(t, \tau)$ of one unit of the discount bond $P_{1}(t, \tau)$ maturing at the investor's horizon, conditional on the information available at date t. Thus $\hat{\sigma}_{\mathrm{J}}(\alpha ; \mathrm{t}, \tau)$, the diffusion vector of the stochastic process $d \hat{\mathrm{J}}(.) / \hat{\mathrm{J}}($.$) , is a measure of the risk associated with$ the random volatility of these contingent Arrow-Debreu prices and thus measures essentially both the volatility of the discount bond price volatility and that of the MPR. Accordingly, the last element in (22) also qualifies as a hedge. It is also investor specific as it depends on both the investor's risk aversion coefficient and his horizon. In a certain way, $\hat{\theta}(\mathrm{t}, \tau)$ plays the role of a state variable that encompasses the random fluctuations of both the reference country yield curve and of the MPR. This is because $\hat{\theta}(t, \tau)$ is linked to both $P_{1}(t, \tau)$ and $h(t)$ and that the latter depends essentially [see equation (17)] on the MPR vector $\phi(t)$. Thus, in that sense, this component can be interpreted as a kind of Merton-Breeden hedging term. However, exactly like the second term in (22), it is a hedge, not against the random shifts of a single state variable, but against the random volatility of the contingent Arrow-Debreu prices $\hat{\theta}(t, \tau)$ relevant to the investor's horizon. Incidentally, notice that the investor's horizon plays here, as in the second term of equation (22), a crucial role in sharp contrast with the classical approach in which investors hedge against instantaneous risks.

It is instructive to compare our results with those obtained by Breeden (1979) in his seminal contribution. In his economy, as in Merton (1973), the investment opportunity set is driven by state variables, thus changes over time in a stochastic manner. Yet, in contrast with Merton, whose CAPM exhibits two (or more) betas, one vis-à-vis the market portfolio and

\footnotetext{
${ }^{20}$ The only models that exhibit this feature are those of Sørensen (1999) and Lioui and Poncet (2000), in which the setting is restricted to a domestic economy. Furthermore, in Sørensen, the yield curve is restricted to obey Vasicek's model and the sole state variable is the spot interest rate.
} 
one (or more) vis-à-vis the state variable(s), his consumption-based CAPM exhibits a single (consumption) beta. This is because the ultimate concern of all investors is real consumption, and that the latter variable encompasses all the sources of risk that affect the economy. His insight thus leads to a parsimonious model that is much more tractable than its multi-betas rivals. Our approach also leads to a portfolio strategy that is "parsimonious" vis-à-vis what is available in the literature and whose implementation is much easier. Indeed, it only involves the estimation of the characteristics of the reference country yield curve and the various market prices of risk rather than those of potentially numerous and generally unknown state variables. In view of Fama's (1998) previously quoted results regarding the identification and pricing of state variables, our finding is empirically important. Our model can be relatively easily implemented. For instance, one can extract from the prices of quoted options or other derivatives the implicit relevant martingale measures by using various numerical methods. Finally, as is apparent in the introduction, it is customary in empirical work to substitute observable state variables (deemed to be "reasonable") for unobservable ones (derived from a theoretical model). But this is sensible only if the latter are clearly identified. Our approach makes this issue irrelevant.

Lastly, turning to the "benchmark" case of the logarithmic utility, equation (23) readily reveals the Bernoulli investor's myopic behavior ${ }^{21}$ : the Merton-Breeden-type dynamic hedge components have disappeared, the investor paying no attention to possible shifts in his (next period) opportunity set. This is well known and was expected, but shows that our decomposition of the investor's strategy into three terms was not arbitrary but grounded on classical portfolio theory. Also, the speculative component is left unaffected, except for the value of the relative risk aversion parameter.

\footnotetext{
${ }^{21}$ The "benchmark" logarithmic utility function has been widely studied in the financial literature. See, among others, Rubinstein (1976) and Long (1990).
} 


\section{Currency risk premium and asset return predictability}

In this section, we examine to what extent the above results impinge on the currency risk premium puzzle and the asset return predictability issue.

a) The classical way to obtain in the investor's optimal strategy hedging terms against currency risk is to assume in an "ad hoc" manner that the exchange rates $\mathrm{e}_{\mathrm{j}}$ are state variables. Our alternative approach has shown that, in a world where interest rates are stochastic and PPP deviations exist due to various imperfections affecting the real sectors of the relevant economies, investors will hedge the fluctuations of the Arrow-Debreu prices $\hat{\theta}(\mathrm{t}, \tau)$. Recall that the latter encompass the random fluctuations of the reference country yield curve and of the MPR $\phi(t)$. Also recall that the volatilities of the relevant exchange rates enter both the numerator and the denominator of $\phi(t)$, and that real interest rate differentials (themselves related to PPP deviations) enter the numerator. Therefore, the third term of equation (22) can (also) be loosely interpreted as a hedge against risks that are related to exchange rate risks. Consequently, this last component may be viewed as justifying currency-related risk hedging on the part of rational investors, i.e. hedging against PPP violation risk. Therefore, in our setting, the presence of currency-related risk hedging is grounded on sound theoretical arguments and need not the somewhat artificial and arbitrary introduction of exchange rates as state variables in the model.

b) To gain further insights and put our results in perspective, consider first a special case in which interest rates and the drifts and diffusion parameters of all the relevant stochastic processes, except those relative to exchange rates, are deterministic. This is the case for instance in Adler and Dumas $(1983)^{22}$. In such a context, the risk associated with $\hat{\mathrm{J}}(\alpha ; \mathrm{t}, \tau)$ stems only from the fluctuations of exchange rates and $\hat{\mathrm{J}}(\alpha ; \mathrm{t}, \tau)$ rewrites:

$$
\hat{\mathrm{J}}(\alpha ; \mathrm{t}, \tau) \equiv \mathrm{E}_{\mathrm{t}}^{\mathrm{P}}\left[\hat{\theta}(\mathrm{t}, \tau)^{\frac{\alpha}{\alpha-1}}\right] \equiv \mathrm{g}\left(\alpha ; \tau, \mathrm{e}_{2}, \ldots, \mathrm{e}_{\mathrm{M}}\right)
$$

Recall from the discussion following equation (19) that in this case, although the first source of risk (interest rate risk) vanishes, the second source of risk associated with the MPR $\phi(t)$

\footnotetext{
${ }^{22}$ Recall that they use nominal, deterministic, interest rates and their PPP deviations stem from random inflation rates affecting variously the different economies.
} 
remains. However, this second source now comprises currency-related, or PPP-related, risk only. In other words, shifts in the investment opportunity set are due solely to random changes in the parameters of the exchange rate processes since the other components of the MPR are deterministic. Consequently, "simple" PPP deviation risk, or "pure" currency risk, occurs in this special case. We stress again that this is obtained without introducing real exchange rates as state variables.

Another special case is the one implicitly used by De Santis and Gérard (1998) and Choi, Hiraki and Takezawa (1998) ${ }^{23}$. Interest rates are stochastic but the drifts and diffusion parameters of all the relevant stochastic processes including those relative to exchange rates are deterministic. In that case, the risk associated with $\hat{\mathrm{J}}(\alpha ; \mathrm{t}, \tau)$ stems only from the fluctuations of real interest rates and $\hat{\mathrm{J}}(\alpha ; \mathrm{t}, \tau)$ rewrites:

$$
\hat{\mathrm{J}}(\alpha ; \mathrm{t}, \tau) \equiv \mathrm{E}_{\mathrm{t}}^{\mathrm{P}}\left[\hat{\theta}(\mathrm{t}, \tau)^{\frac{\alpha}{\alpha-1}}\right] \equiv \mathrm{l}\left(\alpha, \tau ; \mathrm{r}_{1}(\mathrm{t}), \hat{\mathrm{r}}(\mathrm{t})-\mathrm{r}_{1}(\mathrm{t}) 1_{\mathrm{M}-1}\right)
$$

Hence, investors will hedge against real interest rate differentials. Since these differentials are due to PPP deviations and the latter spring from real exchange rates fluctuations, currencyrelated hedging will still take place. Incidentally, the strong empirical relationship between the variations in real interest rate spreads and in real exchange rates is well established (see for instance the recent study by Wu (1999) for real interest and exchange rate differentials between Germany and Japan) so that econometric estimations of these two special cases will yield similar results.

As there is no reason to assume that any of these special cases will occur, it is likely that empirical tests based on them will in general underestimate the size of the currency risk premiums.

c) Turning now to equilibrium considerations, market clearing conditions derived from equation (22) will lead to the equilibrium expected rates of return for the various assets available. Clearly, these rates of return will contain terms that are related to both $\hat{\sigma}_{P_{1}}(t, \tau)$ and $\hat{\sigma}_{\mathrm{J}}(\alpha ; t, \tau)$. By changing the reference country, the $\mathrm{M}$ "national" capital asset pricing models

\footnotetext{
${ }^{23}$ In both papers, currency risk premiums are shown to vary over time. This finding is consistent with the general setting we have adopted here.
} 
will obtain, each one depending on its own representative individual endowed with his relative risk aversion coefficient $\alpha$, albeit all set in an international environment.

d) As evidenced by equation (23), in the special case where investors exhibit logarithmic utility, the equilibrium rates of return will contain pricing factors relative to the $\mathrm{M}$ national market portfolios only. It follows immediately that, in this framework, if the representative individual in each country exists and has a Bernoulli utility, the market price of currency risk must be zero due to the investor's myopia, even though PPP does not hold.

e) In the general case where investors are not myopic, however, the market price of currency risk will not be nil. This is because the expected rates of return on all assets embedded in $\phi(t)$ will, in particular, be influenced by $\hat{\sigma}_{\mathrm{J}}(\alpha ; \mathrm{t}, \tau)$, i.e. by currency-related risk. The latter, which is tantamount to PPP deviation risk, will be hedged at equilibrium, hence priced. Since deviations from PPP imply that the national real spot rates will differ, currency risk is related to the risk involved by the random fluctuations of real interest rate spreads across countries. In theoretical models, currency risk is typically linked to inflation rate differentials ${ }^{24}$. We feel that a model in which it is related to real interest rate differentials is more relevant to the extent that, ultimately, real interest rates are what matter to all investors. We stress however that this result would still obtain under deterministic interest rates, provided real exchange rates remain stochastic. This is because the three matrices $\Lambda_{\mathrm{e}}(\mathrm{t}), \Lambda_{\mathrm{P}}(\mathrm{t})$ and $\Lambda_{\mathrm{S}}(\mathrm{t})$ composing the matrix $\Lambda(\mathrm{t})$ that enters the definition of the MPR $\phi(t)$ would still have non-zero elements ${ }^{25}$.

f) This result also bears on the predictability of asset returns issue. To the extent that PPP violations constitute a systematic risk, currency risk will be priced at equilibrium. Therefore, that part of the risk premium attached to the expected rates of return that is due to currencyrelated risk will be at least partly persistent, making these expected returns partially predictable. One way to interpret our findings is to view them as enriching the set of priced risks that contribute to enhance the predictability of international asset returns. For instance, Beckaert and Hodrick (1992) attempt to characterize predictable components in (excess) returns on equity and foreign exchange markets. One should add to their list, and include in Fama's (1998) one, the (real) spot interest rates and the (real) interest rate differentials.

\footnotetext{
${ }^{24}$ See the survey by Adler and Dumas (1983).

${ }^{25}$ See equations (8), (9) and (10) and the definitions following equation (11).
} 
g) Furthermore, recent empirical evidence for both stocks and bonds strongly suggests that the length of the investment horizon is a very important parameter when assessing whether and to what extent market returns are predictable. In a nutshell, it seems that at short horizons (say, smaller than one year), market returns are essentially unpredictable, as claimed by standard financial theory, while at longer horizons (say, larger than 3 years), they are partially predictable ${ }^{26}$. This could be explained as follows: if short returns are very slightly predictable by some slow-moving variable(s), that predictability adds up as the horizon enlarges. Now the last two terms of equation (22) explicitly depend on the investor's horizon. Therefore, finding out that investment horizons have a direct influence on optimal portfolio allocations, hence on equilibrium rates of return, is both intuitively appealing and consistent with recent empirical evidence.

\section{Concluding remarks}

We have derived the optimal portfolio allocation of an expected utility maximizer in an international context where purchasing power parity does not hold across economies, and where real rates of return on financial assets and real exchange rates follow fairly general diffusion processes driven by an arbitrarily large number of state variables. Using the martingale approach, we have shown that the optimal strategy contains three components, a standard speculative component and only two hedging components, akin to but different from the usual Merton-Breeden terms. The first one is associated with domestic interest rate risk and the second one with the risk brought about by the co-movements of the domestic interest rates and the international market prices of risk. Implementing the optimal strategy thus is much more tractable. Moreover, the investor's horizon is shown to play a crucial role in the optimal strategy design, in contrast with traditional results. The second hedging component depends on real interest rate differentials across countries and encompasses hedging against PPP deviations. In the special case where interest rates remain stochastic but all drifts and volatilities are deterministic, this component is shown to be a pure currency risk hedging component against PPP deviations. Direct consequences of our results are that asset prices include currency risk premiums at equilibrium and that asset returns are more predictable than theory previously asserted. These findings thus have obvious bearing on financial asset

${ }^{26}$ See Cochrane (1999). Note that, according to the study by Bekaert and Hodrick (1992), predictability of exchange rates peaks at six-month horizons and then declines again. 
valuation and portfolio allocation models, both at the theoretical and practical levels. For instance, in a recent paper Kirby (1998) attacks the asset return predictability issue under an interesting new angle. He shows how rational asset pricing models restrict the regressionbased criteria frequently used to measure return predictability. While his empirical tests reveal that NYSE stock portfolio returns are too predictable to be compatible with some wellknown pricing models, he concludes that the overall pattern of predictability across these portfolios seems reasonably consistent with what would be expected when predictability is rational. Our results may also be viewed as supportive of this conclusion.

The scope of this paper could be broadened in at least three different ways. One possible extension is to consider more general preferences. A first step would be to assume a HARA utility function, of which the isoelastic and logarithmic functions are special cases. This would make the results more intricate but still tractable under the complete market assumption. Generalizing preferences further would be much more involved. For instance, Backus, Gregory and Telmer (1993) find that postulating that utility functions exhibit "habit persistence" leads to an overall increase in currency risk premiums. Another, important, extension would be to examine the effects of market incompleteness. This would occur if the number of sources of risk exceeded the number of international assets available for trade. This could be done, but with further restrictive assumptions on the postulated stochastic processes, if the assumption of CRRA utility functions were maintained. Finally, the stochastic processes postulated here for the real exchange rates could be endogenously derived by modeling explicitly the way the real sectors of the national economies involved behave, in particular what (random) production technologies they use and what trade barriers they face. It is likely, however, that the thrust of our results would not be significantly altered by these various generalizations. 


\section{References}

Adler, M., and B. Dumas, 1983, International Portfolio Choice and Corporation Finance: A Synthesis, Journal of Finance 38, 925-84.

Backus, D., A. Gregory and C. Telmer, 1993, Accounting for Forward Rates in Markets for Foreign Currency, Journal of Finance 48(5), 1887-1908.

Balduzzi, P., and A. Lynch, 1999, Transaction Costs and Predictability: Some Utility Cost Calculations, Journal of Financial Economics 52(1), 47-78.

Balduzzi, P., and A. Lynch, 2000, Predictability and Transaction Costs: The Impact on Rebalancing Rules and Behavior, Journal of Finance 55(5), 2285 - 2309.

Barberis, N., 2000, Investing for the Long Run when Returns are Predictable, Journal of Finance 55(1), 225 - 264.

Bekaert, G., and R. Hodrick, 1992, Characterizing Predictable Components in Excess Returns on Equity and Foreign Exchange Markets, Journal of Finance 47(2), 467-509.

Bodnar, G., and W. Gentry, 1993, Exchange Rate Exposure and Industry Characteristics: Evidence from Canada, Japan, and the USA, Journal of International Money and Finance 12(1), 29-45.

Breeden, D., 1979, An Intertemporal Asset Pricing Model with Stochastic Consumption and Investment Opportunities, Journal of Financial Economics 7(3), 265-96.

Brennan, M., E. Schwartz and R. Lagnado, 1997, Strategic Asset Allocation, Journal of Economic Dynamics and Control 21(8-9), 1377-1403.

Chen, N. F., R. Roll and S. Ross, 1986, Economic Forces and the Stock Market, Journal of Business 59(3), 383-403.

Choi, J., T. Hiraki, and N. Takezawa, 1998, Is Foreign Exchange Risk Priced in the Japanese Stock Market? Journal of Financial and Quantitative Analysis 33(3), 361-82.

Choi, J., and A. M. Prasad, 1995, Exchange risk sensitivity and its determinants: a firm and industry analysis of US Multinationals, Financial Management 24, 77-88.

Cochrane, J.H., 1999, New facts in Finance, NBER working paper $n^{\circ} 7169$.

Cochrane, J.H., 1997, Where is the Market Going? Uncertain Facts and Novel Theories, Economic Perspectives XXI: 6, Federal Reserve Bank of Chicago. 
Cooper, I., and E. Kaplanis, 1994, Home Bias in Equity Portfolios, Inflation Hedging, and International Capital Market Equilibrium, Review of Financial Studies 7(1), 45-60.

Cox, J., and C.F. Huang, 1989, Optimal consumption and portfolio policies when asset prices follow a diffusion process, Journal of Economic Theory 49, 33-83.

Cox, J., and C.F. Huang, 1991, A variational problem arising in financial economics, Journal of Mathematical Economics 20, 465-487.

De Bondt, W., and R. Thaler, 1987, Further Evidence on Investor Overreaction and Stock Market Seasonality, Journal of Finance 42(3), 557-81.

De Jong, F., and P. Santa Clara, 1999, The dynamics of the forward interest rate curve: a formulation with state variables, Journal of Financial and Quantitative Analysis 34, 131157.

De Santis, G., and G. Bruno, 1998, How Big Is the Premium for Currency Risk? Journal of Financial Economics 49(3), 375-412.

Domowitz, I, J. Glen, and A. Madhavan, 1998, Country and Currency Risk Premia in an Emerging Market, Journal of Financial and Quantitative Analysis 33, 189-216.

Dumas, B., and B. Solnik, 1995, The World Price of Foreign Exchange Risk, Journal of Finance 50(2), 445-79.

Fama, E., 1998, Determining the Number of Priced State Variables in the ICAPM, Journal of Financial and Quantitative Analysis 33, 217-231.

Fama, E., and R. Bliss, 1986, The Information in Long-Maturity Forward Rates, American Economic Review 77(4), 680-92.

Fama, E., and K. French, 1989, Business Conditions and Expected Returns on Stocks and Bonds, Journal of Financial Economics 25(1), 23-49.

Fama, E., and K. French, 1993, Common Risk Factors in the Returns on Stock and Bonds, Journal of Financial Economics 33(1), 3-56.

Fama, E., and K. French, 1996, Multifactor Explanations of Asset Pricing Anomalies, Journal of Finance 51(1), 55-84.

Fama, E., and K. French, 1998, Value versus Growth: The International Evidence, Journal of Finance 53(6), 1975-99.

Ferson, W., and C. Harvey, 1993, The Risk and Predictability of International Equity Returns, Review of Financial Studies 6(3), 527-566. 
Flood, R., R. Hodrick and P. Kaplan, 1994, An Evaluation of Recent Evidence on Stock Market Bubbles, in Flood R. and P. Garber, Speculative bubbles, speculative attacks, and policy switching, Cambridge and London: MIT Press, 105-33.

Glen, J. and P. Jorion, 1993, Currency hedging for international portfolios, Journal of Finance 48(5), 1865-1886.

Harrison, M. and D. Kreps, 1979, Martingales and arbitrage in multiperiod securities markets, Journal of Economic Theory 20, 381-408.

Harrison, M., and S. Pliska, 1981, Martingales and stochastic integrals in the theory of continuous trading, Stochastic Processes and Their Applications 11, 215-260.

Harvey, C., 1991, The World Price of Covariance Risk, Journal of Finance 46(1), 111-57.

He, J., and L. Ng, 1998, The Foreign Exchange Exposure of Japanese Multinational Corporations, Journal of Finance 53(2), 733-53.

Heath, D., R. Jarrow and A. Morton, 1992, Bond pricing and the term structure of interest rates: a new methodology for contingent claims valuation, Econometrica 60, 77-105.

Hodrick, R., D. Ng and P. Sengmuller, 1999, An International Dynamic Asset Pricing Model, Working Paper 7157, NBER.

Jegadeesh, N. and S. Titman, 1993, Returns to Buying Winners and Selling Losers: Implications for Stock Market Efficiency, Journal of Finance 48(1), 65-91.

Jorion, P., 1990, The Exchange-Rate Exposure of U.S. Multinationals, Journal of Business 63(3), 331-45.

Jorion, P., 1991, The Pricing of Exchange Rate Risk in the Stock Market, Journal of Financial and Quantitative Analysis 26(3), 363-76.

Karatzas, I. and S. Shreve, 1991, Brownian motion and stochastic calculus, Springer Verlag, Second edition.

Kirby, K., 1998, The Restrictions on Predictability Implied by Rational Asset Pricing Models, Review of Financial Studies 11(2), 343-82.

Lamont, O., 1998, Earnings and Expected Returns, Journal of Finance 53(5), 1563-87.

Lioui, A., and P. Poncet, 2000, On Optimal Portfolio Choice Under Stochastic Interest Rates, Journal of Economic Dynamics and Control, forthcoming.

Long, J.B., 1990, The numéraire portfolio, Journal of Financial Economics 26, 29-69. 
Longstaff, F. and E. Schwartz, 1992, Interest Rate Volatility and the Term Structure: A TwoFactor General Equilibrium Model, Journal of Finance 47(4), 1259-82.

Merton, R., 1969, Lifetime Portfolio Selection under Uncertainty: The Continuous-Time Case, Review of Economics and Statistics 51(3), 247-57.

Merton, R., 1971, Optimum Consumption and Portfolio Rules in a Continuous-Time Model, Journal of Economic Theory 3(4), 373-413.

Merton, R., 1973, An Intertemporal Capital Asset Pricing Model, Econometrica 41(5), 86787.

Pliska, S., 1986, A Stochastic Calculus Model of Continuous Trading : Optimal Portfolios, Mathematics of Operations Research 11, 371-382.

Rubinstein, M., 1976, The Strong Case for the Generalized Logarithmic Utility Model as the Premier Model of Financial Markets, Journal of Finance 31, 551-571.

Sercu, P., 1980, A Generalization of the International Asset Pricing Model, Revue de l'Association Française de Finance 1, 91-135.

Solnik, B., 1974, An Equilibrium Model of the International Capital Market, Journal of Economic Theory 8, 500-24.

Solnik, B., 1993, Currency Hedging and Siegel's Paradox: On Black's Universal Hedging Rule, Review of International Economics 1, 180-87.

Solnik, B., 1998, Global Asset Management, Journal of Portfolio Management 24 (4), 43-51.

Sørensen, C., 1999, Dynamic Asset Allocation and Fixed Income Management, Journal of Financial and Quantitative Analysis 34, 513-531.

Stulz, R. M., 1981, A Model of International Asset Pricing, Journal of Financial Economics 9, 383-406.

Vassalou, M., 2000, Exchange rate and foreign inflation risk premiums in global equity returns, Journal of International Money and Finance 19, 433 - 470.

Wu, J., 1999, A Re-examination of the Exchange Rate-Interest Differential Relationship: Evidence from Germany and Japan, Journal of International Money and Finance 18(2), 319-36. 